\title{
Young children's food in Liverpool day-care settings: a qualitative study of pre-school nutrition policy and practice
}

\author{
Ffion Lloyd-Williams ${ }^{1, *}$, Katie Bristow ${ }^{1}$, Simon Capewell ${ }^{1}$ and Modi Mwatsama ${ }^{2}$ \\ 'Division of Public Health, University of Liverpool, Whelan Building, Quadrangle, Liverpool L69 3GB, UK: \\ ${ }^{2}$ Heart of Mersey, Liverpool, UK
}

Submitted 25 June 2010: Accepted 20 February 2011: First published online 19 April 2011

\begin{abstract}
Objective: To explore nutrition and food provision in pre-school nurseries in order to develop interventions to promote healthy eating in early years settings, especially across deprived communities.

Design: An ethnographic approach was used combining participant observation with semi-structured interviews. Research participants were selected purposively using convenience sampling.

Setting: Community pre-school nurseries.

Subjects: Nursery managers $(n 9)$, cooks $(n 6)$, staff ( $n$ 12), parents $(n 12)$ and children at six nurseries (four private and two attached to children's centres) in Liverpool, UK.

Results: Private nurseries had minimal access to information and guidelines. Most nurseries did not have a specific healthy eating policy but used menu planning to maintain a focus on healthy eating. No staff had training in healthy eating for children under the age of 5 years. However, enthusiasm and interest were widespread. The level and depth of communication between the nursery and parents was important. Meal times can be an important means of developing social skills and achieving Early Years Foundation Stage competencies.

Conclusions: Nurseries are genuinely interested in providing appropriate healthy food for under- 5 s but require support. This includes: improved mechanisms for effective communication between all government levels as well as with nurseries; and funded training for cooks and managers in menu planning, cost-effective food sourcing and food preparation. Interventions to support healthy eating habits in young children developed at the area level need to be counterbalanced by continued appropriate national-level public health initiatives to address socioeconomic differences.
\end{abstract}

The period before a child starts school is one of the most critical times in relation to his/her growth and development. It is essential that the child's food offers good-quality nutrition since it provides the foundation required for the growth and development of physiological systems and it sets patterns of eating habits, good or bad, for life. Furthermore, an appropriate diet for children under the age of 5 years is important for their current and continuing health, particularly in terms of preventing obesity and related conditions (diabetes, CVD and common cancers) $)^{(1-5)}$.

Diet is a modifiable lifestyle behaviour that needs to be influenced as early as possible. Eating habits are developed from a very young age, long before children commence primary school ${ }^{(6-8)}$. Given the opportunity and correct dietary exposures, children can learn to eat well and adopt a healthy lifestyle ${ }^{(9)}$. It is therefore crucial that pre-school children are provided with nutritionally balanced meals and that messages about healthy eating are conveyed to parents. This is particularly true if children are to develop the knowledge, understanding and skills needed to make appropriate food choices and develop positive attitudes to a healthy $\operatorname{diet}^{(9)}$.

In England, the number of children attending full day care showed a threefold increase between 1997 and $2006^{(10)}$. The total number of children going to nursery in England and Wales in 2006 was $618300^{(11)}$ and these figures are expected to rise. The expansion of day care means that many young children can receive the majority of their daily nutrients outside the home ${ }^{(12)}$. Typically a child attending full day care can spend $10 \mathrm{~h}$ per d, $5 \mathrm{~d}$ per week for 48 weeks per year in a pre-school setting. Nurseries may thus provide the bulk of a child's nutrition in a day. Therefore pre-school establishments have a crucial responsibility to improve children's nutritional intake, knowledge and attitudes towards a healthy lifestyle. 
Ofsted (the Office for Standards in Education) states that 'food provision in early years settings should provide nutritious food and drink to meet the child's needs, ${ }^{(13)}$ but does not attempt to define the term 'nutritious', instead leaving it open to interpretation. At present the Caroline Walker Trust (CWT; a registered charity that promotes better public health through good food) is widely regarded as the main 'authority' on nursery nutrition. In 1998 the CWT published the first nutritional and practical guidelines in the UK called 'Eating well for under- $5 \mathrm{~s}$ in child care'. These guidelines were subsequently updated and re-launched in $2006^{(14)}$. However, these guidelines are not legally binding or enforceable. Currently, legal requirements offer no nutrient-based standards to guide nurseries on what they should be serving. There are no exclusions or restrictions for less healthy products, such as crisps, processed meat products, biscuits or fried foods, no standards on portion size or fruit and vegetable intake and no regulation concerning snacks ${ }^{(15)}$.

A review of current guidance for nurseries in England, undertaken in 2009 by the School Food Trust, reported that although there is a large amount of guidance being produced, no single source is viewed as authoritative. The School Food Trust therefore highlights the need for a 'more comprehensive, coherent food and nutrition guidance for nurseries that can be accessed easily and be appropriately delivered by all early years settings in England,(16).

Studies carried out in Cheshire and Merseyside in $2006^{(17)}$ and $2007^{(18)}$ showed that: (i) food policies on healthy eating were weak and closely reflect the ambiguity in national guidance; (ii) nursery managers and cooks lacked specific training in early years' nutrition and menu planning; (iii) cooking methods typically increased fat and energy content, and foods were high in salt and sugar; and (iv) the amount of food provided tended to be inappropriate for young children. Similar findings have also been found in other regions in the UK, e.g. Richmond and Twickenham Primary Care Trust ${ }^{(19)}$, Leeds ${ }^{(20)}$ and East Sussex ${ }^{(21)}$. A study by the Soil Association in $2008^{(15)}$ found that nurseries across England and Wales were regularly serving foods not permitted or restricted in schools, including crisps, chocolate, sweets, burgers and chips. Only $8 \%$ of responding nurseries ever served oil-rich fish and only $27 \%$ reported they regularly served water to their children as a drink.

In April 2010 the Local Authorities Government Co-ordinators of Regulatory Services ${ }^{(22)}$ published its findings from a survey of 118 nurseries across twenty-nine local authorities in the England. Findings included excessively high levels of salt, inappropriate portion sizes (either too large or too small) and a lack of starchy carbohydrates. The report recommended that central government should produce clear single-sourced guidance, fund training for nursery staff and make information easily accessible to parents online or via the nurseries. In response to this growing body of evidence, the School Food Trust has set up the Advisory Panel for Food and Nutrition in Early Years with the specific aim of assessing the need for statutory guidance for England ${ }^{(23)}$.

Most research to date has focused on questionnaire surveys with pre-school staff and analysis of menus to identify the nutritional content of food served. Gaps in the literature exist regarding an in-depth understanding of nursery staff's opinions, motivation and perception of their role in influencing young children's food choices and eating habits. Information is also lacking on the role and perception of parents who send their children to nursery; the experiences of children at meal and snack times; and the effect and influence of the nursery environment on food provision.

The purpose of the present research was to conduct an in-depth qualitative exploration of current food provision and nutrition across the early years setting in Liverpool in order to develop a package of interventions which would promote healthy food provision in this sector, especially in deprived communities.

The specific objectives were to:

1. Explore staff's knowledge, opinions, motivation and perceptions.

2. Identify and assess food provision and current practices.

3. Identify the types of food consumed in nurseries.

4. Explore children's experiences of eating in nurseries, by observing meal times and food-related activities.

5. Explore parents' views and perceptions of food provision in nurseries.

6. Explore facilitators that enable the provision of healthy food and potential barriers.

7. Identify a package of interventions to promote healthy eating in pre-school settings in deprived communities.

\section{Methods}

The study was conducted in Liverpool, UK during 2009 and 2010. Ethical approval was granted by the University of Liverpool's Ethics Committee. In order to achieve the aims and objectives of the study it was necessary to work within an adapted ethnographic framework that would enable sufficient in-depth qualitative data to be gathered in a relatively short time. Thus, while the applied nature of the research required clear outcomes relevant to public health policy, an ethnographic approach was used to observe the general and food-related activities of nursery staff and young children in their everyday setting ${ }^{(24)}$.

\section{Sample selection}

The selection of the nurseries for the research involved the cooperation and support of Liverpool City Council and Liverpool Children's Services. Out of an original ten nurseries (four children's centres and six privately run) six 
Table 1 Origin and characteristics of research participants

\begin{tabular}{lccccrr}
\hline & & \multicolumn{5}{c}{ No. interviewed } \\
\cline { 3 - 6 } Nursery code/type & IMD score* & NM, DM and O & Cooks & Nursery staff & Parents & Total \\
\hline NA/private & 46 & 1 NM & 1 & 2 & 2 & 6 \\
NB/private & 907 & 1 NM, 1 O & 1 & 2 & 2 & 7 \\
NC/private & 19353 & 1 NM & 1 & 2 & 2 & 6 \\
ND/private & 8486 & 1 NM, 1 DM & 1 & 2 & 2 & 7 \\
NE/children's centre & 9239 & 1 NM & 1 & 2 & 2 & 6 \\
NF/children's centre & 105 & 2 O & 1 & 2 & 12 & 39 \\
Total & - & 9 & 6 & 12 & 12 & 39 \\
\hline
\end{tabular}

IMD, Index of Multiple Deprivation; NM, nursery managers, DM, deputy managers, O, owners.

*IMD ranks 1 as most deprived and 32482 as least deprived.

were finally selected: two nurseries attached to children's centres (one in an area of mixed socio-economic levels and one in a deprived area) and four privately run nurseries (two serving deprived areas, one in a mixed to affluent area and the fourth in an affluent area). The head teacher from another children's centre was also interviewed as a key informant who could provide important contextual and supplementary information. This children's centre acts as an Early Years Practitioner (EYP) training centre for all types of nursery in Liverpool and in the school holidays supplies some of the other children's centres with lunches.

The research participants within each nursery were selected purposively using a mixture of both specific criteria and convenience sampling ${ }^{(25)}$. Thus, all of the nursery managers and in some cases the deputy managers or owners ( $n 9)$, the head teacher from the other children's centre and all cooks ( $n 6$ ) were interviewed, along with two nursery staff from each nursery $(n 12)$ and two parents from each nursery ( $n$ 12), a total of thirty-nine participants (Table 1). The opportunity to interview across all these different groups allowed a range of perspectives and experiences to be noted, adding strength to the research outcomes ${ }^{(26)}$.

\section{Participant observation and direct observation}

Participant observation was the main methodology employed, but there were also specific times when an activity was directly observed, such as food-related learning activities. During meal times, the researcher acted as participant observer but also on occasions directly observed eating activity.

Two to four hours per day over five working days were spent in each nursery. This allowed observation of the normal daily routine of each nursery in and around specific meal times including breakfast, lunch, morning and afternoon snacks and tea time. It also enabled exploration of the general atmosphere, happiness/contentment of the children and professionalism of the staff. Evidence of health eating posters, toys and activities in the nursery was noted.

Nursery staff were observed conducting a food-related learning activity with the children aged $\geq 3$ years.
Through this, we were able to explore the children's knowledge of different types of food, or at least the extent of their familiarity with what foods are seen as healthy or unhealthy.

All participant and direct observations were written down as near as possible to the time they were conducted. This ensured accurate recall without sitting obtrusively taking notes, which may have caused some inhibition and increased the Hawthorne effect ${ }^{(26)}$.

\section{Interviews}

Semi-structured interviews with the nursery managers/ owners, cooks, staff members and parents were organised at a time and place convenient for the participants. All interviews had standard question topics with additional questions asked as appropriate. The standard topics included participants' understanding of the term 'healthy eating', opinions and perspectives on healthy eating for young children, ways to encourage children to eat and communication with parents/carers. In addition the managers and/or owners were asked about specific training courses for the staff, menu planning, whether the nursery had its own healthy eating policy and guidelines, and the average weekly cost of the food budget. The cooks were also asked about types of food and ingredients used, whether food was prepared from scratch or ready-made, method(s) of cooking, and amount and type of fat, salt and sugar used. Parents were asked about their own child's diet, what type of food the child ate at home, and the level and type of communication with the nursery about their child's eating.

\section{Analysis}

Analysis was an ongoing iterative process where arising themes were used to direct subsequent interviews and observations. Final analysis used a qualitative thematic approach $^{(27)}$ and was conducted using Nvivo 8 software (QSR International (UK) Ltd, Southport, UK). Data from the observations and interviews were systematically coded, charted and mapped. The analysis then sought to identify associations between themes and to carry out an in-depth exploration of the emergent findings. 


\section{Results}

The main themes are discussed under the following headings:

1. Nursery capacity building - access to healthy eating guidance, information and training.

2. Catering environment - menu planning, cook's role, cooking practices and nutritional content, purchasing food and budgets.

3. Children attending the nursery.

4. Nurseries and parents.

The six nurseries are denoted as NA (nursery A) to NF (nursery F) in presenting the results.

\section{Nursery capacity building}

Healthy eating knowledge

All participants were asked what the term 'healthy eating' meant to them. This acted in a limited way to assess their knowledge of healthy eating. The responses given were mixed, with most giving headline 'key messages', such as 'having your five a day' or 'a balanced diet' (four nurseries).

\section{Differences between private sector and children's centre nurseries}

Private nurseries experienced relative isolation. In particular, they lacked access to information and policy guidelines concerning healthy eating for young children. For example, the manager at NC said that they just followed the Ofsted guidelines which mention the need for the provision of a healthy diet but give little in the way of detail:

No. I mean we work on the Ofsted requirements, I mean our whole thing is done really through the Ofsted requirements. (NC manager)

In contrast, the two nurseries attached to the children's centres had access to a wide range of information and advice. This included their colleagues within the centres, in particular health promotion specialists and family support workers.

The main source of information for all nurseries was Nursery World magazine and online sources.

\section{Nursery-level bealthy eating policy and guidelines}

The two children's centre nurseries and one private nursery had heard of the CWT guidelines, but had not seen or utilised them. Only one nursery (NB) had developed a healthy eating policy which was linked into its overall nursery policy and another (NF) was in the process of developing a policy. The other nurseries used their menu planning as the way to maintain a focus on healthy eating:

We have never had really sort of guidelines, we have just sort of planned that we would not have processed foods on the menu really, so you are left then with basic meats, vegetables, potatoes, rice, pasta. (NC manager)

\section{Ofsted 'rolling snacks' strategy}

Nursery staff were asked about the Ofsted strategy recommending 'rolling snacks'. The idea is for children to be able to eat snacks whenever they like during the day as a means of developing their independence. There was concern that this strategy works against healthy eating messages, especially developing an appropriate appetite and oral health. Several of the nursery managers brought this up spontaneously as an area of concern:

No we don't, there is a bit of emphasis coming through about giving them the choice and you know this freedom of whatever. But how on earth do you monitor what they are eating, how do you interact, how do they interact with each other? If someone is playing in a sand pit while someone is having their toast or what have you, how is that a learning experience? It's almost like just pulling into a petrol station. (NF manager)

\section{Training}

Nursery managers, especially in the private sector, felt there were few opportunities for cooks and EYP to attend relevant training courses apart from the compulsory food handling and hygiene courses (four nurseries):

We can't find any you know. It's not that I haven't looked, we did the safer food for better business; I did that about 2 years ago. I sent $\mathrm{X}$ [the cook] on a dental hygiene course, but to be honest nothing, because we can't afford to send anybody on courses that aren't free, and nothing comes through from the city council for any food things. (NB manager)

Over and above training in menu planning and food preparation for those handling and preparing food for young children, the research indicated a need for classroom-based EYP to develop skills in relation to the role of food, eating and meal times within the context of wider early years learning and education:

... it all encourages doesn't it you know, and it makes them see food in a different way doesn't it. And not maybe a chore time where you have got to sit and you know, push all this food into my mouth you know, it can be a fun time as well can't it, yes. Yes. Oh we will have to look out for the training definitely. (NA manager)

\section{Catering environment}

\section{The catering environment}

The four private nurseries all had a kitchen on the nursery premises and a dedicated cook who worked in the mornings for between 3 and $5 \mathrm{~h} / \mathrm{d}$. In NA the role of the cook was a little confused so although the cook started work 
at 08.00 hours to prepare breakfast, cooking did not start until 11.00 hours, giving only an hour to prepare lunch.

The two children's centre nurseries had their meals provided by the kitchen of the attached primary school. The nursery managers therefore did not have direct control over the food provided. Both the managers and the cooks had worked hard with the primary-school head teacher and the catering companies to make the normal school menu appropriate for children under the age of 5 years, and were beginning to see changes:

It's one thing us being over here moaning about the meals coming over, the cook basically had her hands tied, there is only so much she can do, she orders for the school we just have to fit in, it was quite a long, lengthy process but we got there ... I work with quite closely [with the cook's line manager], she actually left me the menus which enables me to go through them, find out what the school are having on what days and I can pick and choose whether it suits me or whether something can be adapted. (NF manager)

\section{Menu planning}

The two children's centres and three of the private nurseries had a 4-week menu plan with seasonal changes developed primarily by the cook in consultation with the nursery manager; the remaining private nursery had a 3-week menu plan. Two nurseries (NB and NC) had consulted a dietitian in order to get the right nutritional requirements for under- $5 \mathrm{~s}$. The rest tended to rely on their existing knowledge and word of mouth.

NE had the most detailed menu which grouped food into categories: main dish, starchy food, vegetables and dessert. This made it easy to see if the menu was balanced. Menus at other nurseries needed more detail to demonstrate appropriate balance of all food groups.

All of the nurseries had the menus available for parents. The two children's centres and NC gave them most prominence. NE had a white board with the day's menu written up for parents to see as they came into the nursery. NF had the day's menu written up in each room, therefore showing the specific meals the different age groups would receive.

\section{Cook's role and experience}

Most cooks were experienced with some having had formal training (NC, ND, NE and NF) through a catering college or via the local council. However, none had specific training on healthy eating in the under- $5 \mathrm{~s}$.

Enthusiasm and interest in cooking for young children were widespread, and seemed to be an important factor in the provision of appropriate healthy food in nurseries. For example:

You could do, I mean I have made, you know the béchamel sauce what goes on the top of lasagne; we were buying that in, the Dolmio, and that was like I think it was £1.79 for one jar of it, and I thought I am going to have a go myself at making it, and it is so easy. All it is flour, it's just the method, you have got get it right ... and then slowly add the milk so it doesn't congeal and go all ... So yes, so I do that now, so I don't have to, we don't buy that in and also it's not full ... well, like [of] all these, all like stabilisers and stuff you know. (NB cook)

\section{Cooking practices and knowledge of nutritional content of food provided}

An indication of whether appropriate meals were being served to the children was the extent to which they were prepared from fresh or frozen unprocessed ingredients. All six nurseries expressed a desire to 'cook from scratch'; certainly none used all processed and/or 'ready-made' products. All used fresh, frozen or tinned vegetables and fruit. If tinned products were used these were of the low/no salt or sugar/syrup varieties. However, tinned tuna was used as a main fish source with a misunderstanding that tinned tuna was rich in $n-3$ fatty acids.

Most cooks did not add salt to their cooking but were regularly using stock cubes, bottled/packet sauces and gravy granules in stews, etc. For example, one cook used gravy and curry mixes without noting the salt and other additives listed on the ingredients labels. Another cook said everything was from scratch but the monthly shopping list revealed that gravy granules and sauce mixes were being used.

\section{Snacks}

Snacks were more likely to be unhealthy processed foods such as sausage rolls, dips, etc. Similarly some puddings were ready-made or from packets, e.g. ice cream and whips. However, two cooks (NA and NE) made their own puddings and controlled the amount of sugars and fats they were using:

We provide cookies or sponge cake with custard which is to me, is quite high in sugar, although I use a lot less sugar. I halve the sugar content that I put in anything, and the fat in the crumble as well I tend to halve. (NE cook)

\section{Budget, time and capacity}

Budget was certainly related to the quality of the ingredients used in terms of what foods are purchased. NC, for example, had the financial capacity to provide good-quality food given it was in an affluent area and governed by the parents:

That [budget for food] all comes out of parent fees, but being a parent funded, parent governed nursery, they set out the budget; they allow us to provide a certain standard of food, because it's their children that they are benefiting. (NC manager) 
Higher quality of food also seemed to be related to more time available to purchase food and greater knowledge of what to buy and where.

\section{Children attending the nursery}

Creating the right atmosphere

In all of the nurseries the children sat together to have their meals and in some nurseries tablecloths were used. The size and type of cutlery and crockery used appeared to help children to eat. One nursery used child-sized brightly coloured cutlery and crockery sets which appeared to encourage good eating practices.

The layout of the nurseries was a factor in creating the right atmosphere. One nursery did not have separate rooms and as many as twenty children of different ages (from 2 to 5 years) - requiring different levels of help with eating - ate together.

One nursery (NF) demonstrated that making meal times fun can help children to eat their food, e.g. the staff wearing different hats each day (fireman's, policeman's, etc.).

\section{Strategies to encourage eating}

The EYP being with the children at meal times and giving gentle encouragement was a consistent practice across the nurseries. When the children, for whatever reason, did not want to eat food, the staff used play to encourage them to eat:

One little girl wouldn't eat her carrots so X [EYP] played a clever game with her. $\mathrm{X}$ said to her 'I bet you can't eat this carrot? Oh you've eaten it!' General laughter from the child and the other children. $\mathrm{X}$ then said that she was going to eat the carrots and put a carrot on a fork and turned her head to speak to the rest of the children while pointing [to] the carrots near to the child. There was then great laughter as the child ate the carrot and $\mathrm{X}$ pretended to be surprised. (NE diary)

\section{Learning and food}

The nurseries did have some activities relating to food or cooking, e.g. home corners. There were some good examples where staff had planned activities around a specific theme throughout the week. In general, observation of classroom-based EYP suggested a greater emphasis could be placed on the role of food, eating and meal times within the context of wider early years learning and social skills development:

$\mathrm{X}$ was doing Goldilocks and the three bears with props, teddies and rag doll, range of chairs and three bowls with oats in them. She had been doing $\mathrm{G}$ and the $3 \mathrm{Bs}$ in some way or another all week. Tomorrow she is doing a Teddy Bears picnic and they will have apples dipped in honey. Children engaged and very responsive. (NF diary)

\section{Social skills development}

Within the Early Years Foundation Stage (EYFS) there are clear links between meal times and the children's personal, social and emotional development, e.g. learning to help set the tables and serve each other.

In four of the nurseries (NB, ND, NE and NF) children were encouraged to serve themselves and each other. The food was brought to the table in serving dishes and the staff then supervised the children serving.

Examples of food-related activity included preparing vegetables to go in a soup or guessing which were the healthy and unhealthy foods with 'Charlie the Healthy Eating Chef':

[Charlie the Healthy Eating Chef] This is a lovely soft toy with a chef's cap, whites and apron. Using Charlie the EYP explains all about healthy eating and how Charlie is a healthy eating chef. She then gets out two soft toy plates, one in green and one in orange, and then a bag of different foods (soft toys). She then asks the children to take out a food from the bag, decide whether it should be on the green plate or the orange plate. The green plate signifies foods that are good and can be eaten at any time; the orange plate signifies foods that can be eaten but only occasionally as a treat. The children take turns deciding which food goes on to which plate. One child whenever he picks out a cake, sweet or chips because he likes them thinks they should go on the green plate. $\mathrm{X}$ uses this to explain the difference between what you like and what is good for you. (NE observation)

\section{Nurseries and parents}

\section{Parent and nursery relationship}

The level and depth of communication between the nursery and the parents was important regarding what the child had eaten both at home and at the nursery. This allowed both parents and nursery staff a degree of discretion in deciding if a child was not hungry or in fact needed encouraging to eat something.

Some parents actively sought advice from the nursery concerning what and how their child was eating. In particular the cook would be asked how to make different dishes. This was especially the case for a first child:

When X [child] first started here, they were giving him things that I hadn't yet tried him with ... wouldn't have known to or was a bit wary of giving him. So when I said 'Oh he hasn't had that before', and they were like 'Oh are we doing wrong?'; so I said no, as long as I know that he is fine with it now I can give it to him myself. (NE parent 1) 


\section{Discussion}

The adapted ethnographic approach taken in the present study has provided a rich stream of evidence that begins to address the underlying reasons why some nurseries might already be making concerted efforts to improve their meal provision compared with others that are experiencing tougher barriers. Furthermore, the findings reported here are largely consistent with other studies conducted in the last few years in the UK at national ${ }^{(15,22)}$, regional $^{(19-21)}$ and local levels ${ }^{(17,18,28)}$. These studies suggest that meals and snacks provided to children in some nursery schools contain excess saturated fat, salt and sugar and also lack some essential nutrients such as $\mathrm{Fe}$ and $\mathrm{Zn}$. Some of the factors that may contribute to inappropriate food provision include the fact that many nurseries' food policies on healthy eating are weak, there is a lack of training on healthy eating for catering managers and a general lack of awareness and action to reduce excess saturated fat, salt and sugar in foods served to children. A quantitative survey ${ }^{(28)}$, carried out in Liverpool within the same time frame as the present study, raised key issues relating to the need for clear national statutory guidance and training for nursery staff, especially managers and cooks. Based on this accumulating body of evidence, the Department of Education recently set up an Advisory Panel for Food and Nutrition in Early Years which will make recommendations to the Department about food and nutrition guidance for early years settings in England ${ }^{(23)}$.

A wide range of nurseries across Liverpool provided quantitative data on the nutritional content of meals and assessment of cooking practices. This is vital information for understanding the extent of the problem and gives an indication of the amount of resources that might be needed to make real changes. The advantage of having the two studies running in parallel is that this has generated evidence with both breadth and depth. Spending a week in each nursery enabled the examination of the individual context of each of the six nurseries. For example, we found clear differences between children's centres and private nurseries, and also differences between private sector nurseries. Differences between private nurseries were dependent on how they were run (i.e. needing to make a profit or breaking even, being owned by one person $v$. being governed by a committee). Where nurseries were owned by one person and profit making, restrictions on the food budget were apparent and this in some instances affected the quality of food provided (mainly processed). In contrast, while children's centres had access to resources which enabled greater emphasis on healthy eating for under-5s (e.g. health promotion specialists and family support workers), they relied on attached primary schools to provide meals which in many cases were not suitable for the under- $5 \mathrm{~s}$ in their care. Therefore, while private nurseries had the autonomy to ensure correct food provision, they felt constrained by budgets; and while children's centres were not constrained by budget or resources, they did not have the autonomy to necessarily provide suitable food for the under- $5 \mathrm{~s}$ in their care.

Being in the nursery for an extended period demonstrated the centrality of the nursery-parent relationship in developing a healthy eating culture in the nursery. It also raised the potential for such a culture to spread beyond the nursery setting into the children's homes. Spending time with various staff members and in particular the cook and manager enabled witnessing at first hand how knowledge and experience can make a difference. Similarly, observing children's meal times revealed that use of brightly coloured child-sized cutlery and crockery encouraged children to eat their food and that the unwieldy nature of adult-sized cutlery in small hands clearly made eating difficult. This type of attention to detail is also an example of the practical way nurseries can work towards developing the children's social skills. The evidence from the present study also emphasised the key role food and meal times can play in achieving EYFS targets. The way food and meal times are an interrelated aspect of learning also came out in the specific foodrelated activities observed.

It was possible to see the different ways in which the EYP encouraged children to eat their food, through gentle encouragement and by making meal times fun. It was also possible to see why some recommendations may not work well in practice. Although attractive in theory, the idea for staff to eat their meals alongside children is problematic. Logistically, it would mean staff either having to bend over to eat at a low table or balance a hot plate of food on their knee while on a child-sized chair. This would make the supervision of children with differing eating abilities difficult.

The semi-structured interviews were an opportunity to explore specific issues in depth and clarify issues noted during observation. For example, the confusion over 'all day snacking' brought out the need for clear communication, especially between government departments.

All of the findings demonstrate the complex way different issues work together to support or hinder a nursery to develop a healthy eating culture. Social and economic factors are important (e.g. previous exposure of staff and parents to healthy eating, the accessibility of appropriate and affordable ingredients). Yet other issues operate independently and are found across all the nurseries (e.g. the knowledge and experience of the cook).

Childhood obesity is the most serious and growing challenge for health-care services, potentially leading to obese adults at increased risk of diabetes, CVD and cancer with a reduced life expectancy. After the age of 3 years, the likelihood that obesity will persist into adulthood increases with advancing age of the child and is even higher in children with severe obesity. After an obese child reaches 
6 years of age, the probability that obesity will persist into adulthood exceeds $50 \%$; worse, $70-80 \%$ of obese adolescents will remain obese as adults ${ }^{(29)}$.

The latest UK Department of Heath figures are alarming, showing that one in four children starting primary school in England is either overweight or obese ${ }^{(30)}$. Various government policy documents, service frameworks and toolkits have therefore been published recently highlighting a need for work across the early years (a critical period for children in the development of food preferences and eating patterns) $)^{(31-34)}$.

There are many factors contributing to obesity in childhood, including genetics and environmental factors. However, an unhealthy diet combined with a lack of exercise is regarded as the main cause. Diet is a modifiable lifestyle behaviour which needs to be influenced as early as possible because eating habits are developed from a very young age, long before children commence primary school $^{(6-8)}$. Given the opportunity and correct dietary exposures, children can learn to eat well and adopt a healthy lifestyle ${ }^{(9)}$. It is therefore crucial that nursery-school children are provided with nutritionally balanced meals and that clear messages about healthy eating are conveyed to parents. This is particularly true if children are to progressively develop the knowledge, understanding and skills needed to later make their own appropriate food choices and develop positive attitudes to a healthy diet.

\section{Study limitations}

The qualitative nature of the present study, using ethnographic data from six nurseries, implied that generalisation to a wider context was not expected. However, the findings are reassuringly consistent with the quantitative study conducted in Liverpool and also other studies across England. Inevitably the study would have been strengthened if a greater range of nurseries had participated to ensure saturation of themes ${ }^{(26)}$. Having more than one ethnographer working in the nurseries might have provided a useful comparison across the identified themes. These inputs were not possible with the time and resources available for the study. Nevertheless, a clear strength of the study is the in-depth contextual and explanatory nature of the evidence. This type of evidence can help to guide the development of specific interventions to help improve healthy eating provision across the early years sector.

\section{Conclusions}

The present findings suggest the urgent requirement for a statutory framework to provide supportive policy and practical guidance. At the nursery level, there needs to be the organisational capacity to provide the human, material and economic resource capacity to ensure that meals are healthy and children will want to eat them.
This includes a clear lead by the manager, appropriately trained and experienced staff (cooks and EYP), adequate equipment and facilities, and a sufficient catering budget. Interventions to support healthy eating habits in young children developed at the area level by primary care trusts and local authorities will need to be counterbalanced by continued appropriate national-level public health initiatives to address socio-economic and cultural differences.

\section{Acknowledgements}

The study was funded by MerseyBEAT, a collaboration between Liverpool Primary Care Trust and the University of Liverpool. None of the authors has any commercial, personal, political or academic conflicts of interest. F.L.-W. conceived and managed the research project, supervised K.B., participated in analysis of the data, and wrote and edited the manuscript. K.B. carried out the interviews and observations in the nurseries, conducted the qualitative analysis, and contributed to the editing of the manuscript. M.M. was a co-investigator, contributing to project delivery, and read and revised all versions of the manuscript. S.C. was a co-investigator, contributing to project delivery, and read all versions of the manuscript and provided detailed revision. The authors would like to acknowledge and thank all the nurseries, nursery staff and parents who took part in the study.

\section{References}

1. Bundred P, Kitchiner D \& Buchan I (2001) Prevalence of overweight and obese children between 1989 and 1998: population based series of cross sectional studies. BMJ 322, 326-328.

2. Goran MI (2001) Metabolic precursors and effects of obesity in children: a decade of progress, 1990-1999. Am J Clin Nutr 73, 158-171.

3. Kotani K, Nishida M, Yamashita S et al. (1997) Two decades of annual medical examinations in Japanese obese children: do obese children grow into obese adults? Int J Obes Relat Metab Disord 21, 912-921.

4. Whitaker RC, Wright JA, Pepe MS et al. (1997) Predicting obesity in young adulthood from childhood and parental obesity. N Engl J Med 337, 869-873.

5. Caballero B (2001) Early nutrition and risk of disease in the adult. Public Health Nutr 2, 335-336.

6. Jacobi C, Agras WS, Bryson S et al. (2003) Behavioral validation, precursors, and concomitants of picky eating in childhood. J Am Acad Child Adolesc Psychiatry 42, 76-84.

7. Liem DG \& Mennella JA (2002) Sweet and sour preferences during childhood: role of early experiences. Dev Psychobiol 41, 388-395.

8. Mennella JA, Ziegler P, Briefel R et al. (2006) Feeding Infants and Toddlers Study: the types of foods fed to Hispanic infants and toddlers. J Am Diet Assoc 106, Suppl. 1, S96-S106.

9. Thomas J, Sutcliffe K, Harden A et al. (2003) Children and Healthy Eating: A Systematic Review of Barriers and Facilitators. London: EPPI-Centre, Social Science Research Unit, Institute of Education, University of London; available at http://eppi.ioe.ac.uk/EPPIWebContent/hp/reports/healthy_ eating02/Final_Report_web.pdf 
10. Foresight (2007) Tackling Obesity: Future Choices - Project Report, 2nd ed. London: Government Office for Science, Department of Innovation Universities and Skills; available at http://www.bis.gov.uk/assets/bispartners/foresight/docs/ obesity/17.pdf

11. Welsh Assembly Government (2007) Schools in Wales: General Statistics 2007. Cardiff: Welsh Assembly Government; available at http://wales.gov.uk/cisd/publications/statspubs/ schoolsgeneral2007/doc.pdf?skip $=1$ \&lang $=$ en

12. Pre-school Learning Alliance (2006) Act Now to bridge the early years nutrition gap says Alliance, as it launches new training scheme for practitioners. Press release, 26 January. http://www.pre-school.org.uk/media/press-releases/54/actnow-to-bridge-the-early-years-nutrition-gap-says-alliance-asit-launches-new-training-scheme-for-practitioners (accessed May 2010).

13. Department for Education and Skills (2005) Healthy School Lunches for Pupils in Nursery Schools/Units. Guidance for School Caterers on Implementing National Nutrition Standards. Nottingham: DfES Publications; available at http://www. dcsf.gov.uk/schoollunches/downloads/H01530Nursery.pdf

14. Crawley H (2006) Eating Well for Under-5s in Child Care: Practical Nutritional Guidelines, 2nd ed. St Austell: Caroline Walter Trust; available at http://www.cwt.org.uk/ pdfs/Under5s.pdf

15. Organix \& Soil Association (2008) Georgie Porgie Pudding and Pie: Exposing the Truth about Nursery Food. Bristol: Organix \& Soil Association; available at http://www. soilassociation.org/LinkClick.aspx?fileticket $=$ P7\%2F0qfiUPe4 $\% 3$ D\&tabid $=388$

16. Sharp L, Mucavele P \& Nelson M (2010) Preliminary Review of Early Years Food, Nutrition and Healthy Eating Guidance in England: A Summary. London: School Food Trust.

17. Heart of Mersey (2006) Nursery Food Provision, Policy and Practice across Cheshire and Merseyside. Report of a Survey of Food Provision in Nurseries across Cheshire and Merseyside to Support the Big Noise Social Marketing Project. Liverpool: Heart of Mersey; available at http:// www.heartofmersey.org.uk/uploads/documents/nov_06/ hom_1162897023_HoM_Nursery_Food_Provision,_Po.pdf

18. Sefton Council (2007) Food and Nutrition in Nursery Settings: Project Report 2006-2007. Southport: Sefton Council, Environmental Protection; available at http:// www.sefton.gov.uk/pdf/epd_nursery\%20analysis.pdf

19. Shaw J \& Mindlin M (2006) Are Children in Childcare Given Snacks which Comply with National Guidelines? Teddington: Richmond and Twickenham PCT, St Georges University of London.

20. Moore $\mathrm{H}$, Nelson $\mathrm{P}$, Marshall $\mathrm{J}$ et al. (2005) Laying foundations for health: food provision for under $5 \mathrm{~s}$ in day care. Appetite 44, 207-213.

21. East Sussex County Council (2007) Nipper's Nutrition: A Study into the Nutritional Quality of Meals Provided by Local Nurseries for Children Less Than Five Years Old. Lewes: East Sussex County Council Trading Standards Service; available at http://www.eastsussex.gov.uk/NR/
rdonlyres/C5871E40-570B-41EC-9FCA-6D022FDB5F20/0/ nippersnutrition.pdf

22. Local Authorities Government Co-ordinators of Regulatory Services (2010) Councils working with nurseries to improve nutritional standards. London: LACORS; available at http://www.lacors.gov.uk/lacors/upload/24525.doc

23. School Food Trust (2010) Advisory Panel on Food and Nutrition in Early Years. http://www.schoolfoodtrust.org. $\mathrm{uk} /$ research/advisory-panel-on-food-and-nutrition-in-earlyyears (accessed May 2010).

24. Lambert H \& McKevitt C (2002) Anthropology in health research: from qualitative methods to multidisciplinarity. BMJ 325, 210-213.

25. Ritchie J, Lewis J \& Elam G (2003) Designing and selecting samples. In Qualitative Research and Practice: A Guide for Social Science Students and Researchers, pp. 77-108 [J Ritchie and J Lewis, editors]. London: Sage Publications.

26. Kuper A, Reeves S \& Levinson W (2008) An introduction to reading and appraising qualitative research. BMJ 337, a288.

27. Seale C (editor) (2004) Coding and analysing data. In Researching Society and Culture, pp. 305-321. London: Sage Publications.

28. Parker M, Dexter N, Kelly A et al. (2010) Nursery Nutrition and Food Provision in Liverpool Final Report. Liverpool: Liverpool First For Health and Wellbeing Partnership.

29. Segal DG \& Sanchez JC (2001) Childhood obesity in the year 2001. Endocrinologist 11, 296-306.

30. Dinsdale H \& Ridler C (2010) National Child Measurement Programme: Change in Children's Body Mass Index between 2006/07 and 2008/09. Oxford: National Obesity Observatory.

31. Department of Health (2004) Choosing Health: Making Healthier Choices Easier. London: The Stationery Office; available at http://webarchive.nationalarchives.gov.uk/+/ www.dh.gov.uk/en/Publicationsandstatistics/Publications/ PublicationsPolicyAndGuidance/DH_4094550

32. Department for Education and Skills \& Department of Health (2006) National Service Framework for Children, Young People and Maternity Services: The Mental Health and Psychological Wellbeing of Children and Young People. London: DH Publications; available at http:// www.dh.gov.uk/prod_consum_dh/groups/dh_digitalassets/ @dh/@en/documents/digitalasset/dh_4090560.pdf

33. Swanton K \& Frost M (2007) Lightening the Load: Tackling Overweight and Obesity. A Toolkit for Developing Local Strategies to Tackle Overweight and Obesity in Children and Adults. London: National Heart Forum in association with the Faculty of Public Health; available at http:// www.kentsport.org/pdfs/obesity_toolkit_full.pdf

34. Cross-Government Obesity Unit, Department of Health \& Department of Children, Schools and Families (2008) Healthy Weight, Healthy Lives: A Cross-Government Strategy for England. London: DH Publications; available at http://www.dh.gov.uk/prod_consum_dh/groups/ dh_digitalassets/documents/digitalasset/dh_084024.pdf 